\title{
Analysis of Weak Links in E-commerce Logistics Industry Chain Based on DEA
}

\author{
Xun Zhang, ${ }^{1,}$, Maoxiang Lang ${ }^{*}, 1, \mathrm{~b}$ and Xuefei $\mathrm{Li}^{2, \mathrm{c}}$ \\ 1School of Beijing Jiaotong University, Beijing 100044, China; \\ ${ }^{2}$ China Academy of Railway Sciences Corporation Limited, Beijing 100015, China. \\ a16120934@bjtu.edu.cn, b, ${ }^{*}$ mxlang@bjtu.edu.cn, ${ }^{\circ}$ carslxf@126.com
}

\begin{abstract}
According to the development status of e-commerce logistics industry in Yuhong District of Shenyang, this paper combines the components of e-commerce logistics industry chain and uses DEA (Data Envelopment Analysis) to develop the e-commerce logistics industry in Yuhong District and other districts and counties in Shenyang. The effectiveness of the industrial chain is judged and the weak links in the e-commerce logistics industry chain in Yuhong District is analyzed. Finally, the corresponding industrial chain improvement plan is proposed for the existing weak links.
\end{abstract}

Keywords: E-commerce; logistics; DEA; weak links; promotion.

\section{Introduction}

China attaches great importance to the development of e-commerce logistics. Since 2016, China has issued more than a dozen documents to encourage the development of e-commerce logistics industry. On March 17, 2016, the Ministry of Commerce issued the "National E-Commerce Logistics Development Special Plan (2016-2020)". The "Planning" proposed seven main tasks and eight key projects. By 2020, it will basically form an e-commerce logistics system with "complete layout optimized structure, powerful functions, efficient operation and high-quality service". And it will made significant progress in the development of informationization, standardization and intensification. However, in the process of e-commerce logistics development, there has been a blind expansion of the industrial scale, extensive introduction of enterprises, resulting in serious homogenization competition of e-commerce enterprises, the industrial chain has broken. How to rationally arrange related enterprises according to the existing e-commerce logistics industry, and make the input and output of the e-commerce logistics industry chain optimal has become an urgent problem to be solved.

\section{Relevant Theoretical Analysis}

Data envelopment analysis (DEA) is an efficient evaluation method for multiple decision-making units with multiple inputs and outputs. The model has been widely used in the fields of management science and systems engineering to study the relative effectiveness of productive sectors with multiple inputs and outputs. In this study, several districts of Shenyang with better development are selected for the e-commerce logistics industry chain, and make the selected districts together to constitute the DMU comparison set. After selecting the DMU, the output indicators of the industry chain are selected. The important links selected by e-commerce logistics industry chain are input and analyzed separately as input indicators. The output efficiency of each input index in the industrial chain of the Yuhong industry is analyzed, and then the direction to improve the industrial chain will be found.

In the analysis of e-commerce logistics industry chain, the n-1 districts and Yuhong District are decision-making units, then the industry chain supply and output rate model have a total of $n$ decisionmaking units, recorded as $\mathrm{DMU}_{i}, \mathrm{i}=1,2, \ldots, \mathrm{n}$. The $\mathrm{J}$ principal component indexes of the logistics supply resource of the $\mathrm{i}$-th decision-making unit are input into the model as the input resource, and is denoted as $X_{i j}=\left[x_{\mathrm{i} 1}, x_{\mathrm{i} 2}, \ldots, x_{\mathrm{ij}}\right]^{T}$, where $\mathrm{i}=1,2, \ldots, \mathrm{n} ; \mathrm{j}=1,2, \ldots, \mathrm{J}$. The K principal component indexes of the logistics demand resource are selected as the output resource of the model, denoted by $Y_{i j}=\left[y_{\mathrm{i} 1}, y_{\mathrm{i} 2}, \ldots, y_{\mathrm{ij}}\right]^{T}$, where $\mathrm{i}=1,2, \ldots, \mathrm{m} ; \mathrm{k}=1,2, \ldots, \mathrm{K}$. The supply resource utilization rate of the $\mathrm{r}$-th decision unit is denoted as $\theta_{s}^{\prime}$, then the solution model of $\theta_{s}^{\prime}$ is: 


$$
\left\{\begin{array}{c}
\min \left(\theta_{s}^{\prime}-\varepsilon\left(e_{1}^{T} s^{-}+e_{2}^{T} s^{+}\right)\right) \\
\sum_{j=1}^{10} X_{j} \lambda_{j}+s^{-}=\theta_{s}^{\prime} X_{r} \\
\sum_{j=1}^{10} Y_{j} \lambda_{j}-s^{+}=Y_{r} \\
\lambda \geq 0, j=1,2, \ldots, \mathrm{n} \\
s^{-} \geq 0 ; s^{-} \geq 0
\end{array}\right.
$$

If $\theta_{S}^{\prime}<1$, it is means that there is a DMU, whose output is higher than the output of the i-th DMU, and the input is lower than the output of the i-th DMU. If $\theta_{s}^{\prime}=1$, then the size and technology of the i-th decision unit are valid at the same time.

\section{Case Study}

\subsection{Introduction to the Scale of E-commerce Industry}

In recent years, the development of e-commerce industry in Yuhong District is rapid. In 2016, the total volume of e-commerce transactions in Yuhong District was 3.6 billion yuan, with an annual growth of $42 \%$, of which online shop sales were 680 million yuan, accounting for $18.9 \%$. But the economic development of Yuhong District is at a medium level in Shenyang, it is estimated that the e-commerce transaction volume will reach 30.9 billion yuan in 2022, indicating that there is still room for the improvement in e-commerce of Yuhong District.

\subsection{Analysis of the Weak Links in the Industrial Chain}

In this paper, we choosed another 9 districts of Shenyang to compare with Yuhong district. And seven input indicators and 2 output indicators were selected based on the availability of data. The data comes from the ICP code business directory provided by Shenyang Industrial and Commercial Bureau and the Shenyang Statistical Yearbook. The relevant data are shown in Table 1.

Table 1. DEA model input and output indicators list of E-commerce industry chain

\begin{tabular}{|c|c|c|c|c|c|c|c|c|c|}
\hline \multirow[b]{2}{*}{$\begin{array}{c}\text { Means } \\
\text { Standard } \\
\text { Area } \\
\text { county }\end{array}$} & \multicolumn{7}{|c|}{ Input indicators } & \multicolumn{2}{|c|}{ Output indicators } \\
\hline & $\begin{array}{c}\text { Number } \\
\text { of B2B } \\
\text { companies }\end{array}$ & $\begin{array}{l}\text { Number of } \\
\text { B2C } \\
\text { Enterprises }\end{array}$ & $\begin{array}{l}\text { number } \\
\text { of O2O } \\
\text { shops }\end{array}$ & $\begin{array}{l}\text { Number } \\
\text { of third- } \\
\text { party } \\
\text { trading } \\
\text { platforms }\end{array}$ & $\begin{array}{c}\text { Number } \\
\text { of } \\
\text { online } \\
\text { stores } \\
\text { with } \\
\text { ICP } \\
\text { code }\end{array}$ & $\begin{array}{l}\text { Number } \\
\text { of } \\
\text { Internet } \\
\text { users }\end{array}$ & $\begin{array}{l}\text { Number } \\
\text { of } \\
\text { mobile } \\
\text { phone } \\
\text { users at } \\
\text { the end } \\
\text { of the } \\
\text { year }\end{array}$ & $\begin{array}{l}\text { The } \\
\text { added } \\
\text { value of } \\
\text { the } \\
\text { tertiary } \\
\text { industry }\end{array}$ & $\begin{array}{l}\text { The total } \\
\text { retail } \\
\text { sales of } \\
\text { social } \\
\text { consumer } \\
\text { goods }\end{array}$ \\
\hline Yuhong & 203 & 10 & 1860 & 10 & & 7 & 131207 & 1564025 & 1016564 \\
\hline Shenhe & 196 & 14 & 7178 & 16 & 275 & 50953 & 328257 & 8056049 & 10417681 \\
\hline Heping & 141 & 166 & 6686 & 50 & 301 & 46659 & 300595 & 6986883 & 7945314 \\
\hline Tiexi & 230 & 18 & 5670 & 5 & 147 & 65051 & 419081 & 3234334 & 5831654 \\
\hline Huanggu & 158 & 12 & 3726 & 14 & 84 & 58539 & 377127 & 3638855 & 3063729 \\
\hline Dadong & 115 & 5 & 4233 & 0 & 102 & 48806 & 314426 & 2103053 & 2826994 \\
\hline Hunnan & 73 & 28 & 2262 & 21 & 112 & 13045 & 114765 & 1497311 & 1721853 \\
\hline Sujiatun & 37 & 7 & 782 & 1 & 54 & 55924 & 329153 & 1016793 & 1515957 \\
\hline Xinmin & 17 & 6 & 3770 & 5 & 30 & 80100 & 487000 & 1034447 & 1323855 \\
\hline Liaozhong & 22 & 1 & 3770 & 0 & 15 & 68421 & 332061 & 980038 & 1045834 \\
\hline
\end{tabular}

The above indexes and related values were input into the DEA model for calculation. The evaluation results are shown in Table 2. 
Table 2. DEA model evaluation results

\begin{tabular}{ccc}
\hline County & $\theta_{S}^{\prime}$ optimal value & Evaluation conclusion \\
\hline Yuhong & 0.749225 & Non-DEA effective \\
Shenhe & 1 & DEA effective \\
Heping & 1 & DEA effective \\
Tiexi & 1 & DEA effective \\
Huanggu & 1 & DEA effective \\
Dadong & 1 & DEA effective \\
Hunnan & 0.725965 & Non-DEA effective \\
Sujiatun & 1 & DEA effective \\
Xinmin & 1 & DEA effective \\
Liaozhong & 1 & DEA effective \\
\hline
\end{tabular}

The evaluation results show that, except Yuhong District and Hunnan District, the e-commerce input and output of the other districts and counties in are all DEA effective. This reflects that there is an imbalance in the development of various links in the industrial chain in the development of ecommerce in the Yuhong District. Due to the low utilization rate of supply resources in the ecommerce industry chain, the actual input and output are not proportional.

The shadow price of DEA analysis results can indicate whether there is an additional investment value of an input resource. The shadow prices of three types of e-commerce enterprises in 10 districts and counties are shown in Table 3.

Table 3. DEA shadow price list of three types of e-commerce enterprises

\begin{tabular}{cccc}
\hline County & Dual Price $(\mathrm{B} 2 \mathrm{~B})$ & Dual Price $(\mathrm{B} 2 \mathrm{C})$ & Dual Price $(\mathrm{O} 2 \mathrm{O})$ \\
\hline Yuhong & -0.02221688 & 0 & -0.00053763 \\
Shenhe & -0.00124496 & 0 & -0.00001570 \\
Heping & -0.00336632 & 0 & -0.00001239 \\
Tiexi & -0.00000548 & 0 & -0.00002422 \\
Huanggu & -0.00275621 & 0 & -0.00003475 \\
Dadong & 0 & 0 & -0.00009993 \\
Hunnan & 0 & 0 & 0 \\
Sujiatun & -0.00330844 & 0 & -0.00011502 \\
Xinmin & -0.02167031 & 0 & -0.00008215 \\
Liaozhong & -0.01023375 & 0 & -0.00012902 \\
\hline
\end{tabular}

Table 3 shows that the shadow price of B2C enterprises in Yuhong District is 0 , indicating that the number of B2C enterprises in Yuhong District type is near saturation, the potential of market to further expand is lower. And the shadow price of $\mathrm{B} 2 \mathrm{~B}$ business and $\mathrm{O} 2 \mathrm{O}$ business in Yuhong District are both negative, , indicating that the increase in the number of $\mathrm{B} 2 \mathrm{~B}$ enterprises and $\mathrm{O} 2 \mathrm{O}$ shops will make the overall output efficiency of e-commerce been improved in Yuhong District.

\subsection{Improvement Plan}

\subsubsection{Focus on Attracting B2B Business Enterprises}

The Yongan E-commerce Building and public service platform planning should be completed quickly and the construction speed should be improved. Special activities should be carried out to attract investments of large-scale B2B e-commerce enterprises . Investment promotion strategies and policies should be made to effectively attract enterprise to create quality integrated service capabilities and service environments. The introduction of large-scale electric business enterprises should be speeded up through the theme investment, exhibition investment and commissioned investment to build a B2B e-commerce platform operation and settlement center base in Shenyang and serves the Northeast of China.

\subsubsection{Rapid Development of O2O E-commerce}

The environmental attraction, policy guidance, administrative control and other comprehensive means should be used to support the existing e-commerce enterprise to become bigger and stronger through transformation and upgrading. The cooperation between the existing large-scale professional market, logistics and distribution enterprises and large-scale well-known domestic enterprises 
should be promoted. The e-commerce transaction service projects should be introduced and developed independently to accelerate the transformation of e-commerce enterprises. The channels of the existing business platform should go down to link with the industry, while promoting the physical stores to transform and innovate the business model. The business pattern should be innovated to promote the omni-channel competition in advance, vigorously develop the online and offline interaction of $\mathrm{O} 2 \mathrm{O}$, and enhance the new impetus for economic development.

\subsubsection{Vigorously Consolidate the Foundation of B2B2C E-commerce Logistics}

The e-commerce application ratio of enterprises in Yongan New City should be improved, especially for small and medium enterprises. The development and application of e-commerce service industry should be promoted to guide the logistics and industrial SMEs in the market to apply ecommerce means to produce and operate, to break the time and space constraints between producers, sellers and consumers, and to realize online and offline distribution of information, goods, technology and services. The sharing of global supply and demand information resources between enterprises should be promoted to make direct supply and demand transactions between the supply and demand sides through "buy globally and sales globally", reduce the comprehensive cost of advertising, procurement, marketing and other links, improve the scope and efficiency of transactions. Convenient and fast e-commerce logistics distribution system and safe and reliable electronic payment system should be utilized to complete goods-delivery, to reduce inventory, transportation and sales costs, and to promote enterprises to participate in fair competition to accelerate its development.

\section{Summary}

This paper uses DEA model and selects indicators to quantitatively analyze the weak links of ecommerce logistics industry chain in Yuhong District of Shenyang City. From the theoretical point of view, it is determined that the current e-commerce logistics industry chain is not DEA effective. And through DEA shadow price analysis it is found that, at present, the weak link in the logistics industry chain is a short of B2B enterprises and $\mathrm{O} 2 \mathrm{O}$ enterprises, and finally the corresponding improvement plan is given. This method makes up for the lack of qualitative analysis, and is conductive to the rational introduction and allocation of resources by the government departments in the process of regional development to achieve coordinated development of the logistics industrial chain.

\section{References}

[1]. Ministry of Commerce. National E-Commerce Logistics Development Special Plan (2016-2020). 2016-03-23.

[2]. State Department. Medium and long-term planning for the development of the logistics industry (2014-2020). 2014-10-14.

[3]. Shenyang Municipal Bureau of Statistics. 2015 Shenyang Statistical Yearbook. 2015.

[4]. Liming He, Xiaodong Zhang, Zengrong Ma. China Logistics Technology Development Report.2016.

[5]. Junnian $\mathrm{Wu}$, Jinghua Meng, Meng Wu, Chengliang Li. Construction and Optimization of Circular Economy Industry Chain Based on DEA Model. Environmental Engineering. Vol. 03 (2015), p. 149-152.

[6]. Qiongwei Ye, Qiuyun Nie. The Construction of E-commerce Development Level Measurement Index System and Its Empirical Study on the Impact of China's Service Industry. E-commerce. Vol. 11 (2013), p. 28-29+43.

[7]. Meijuan Li, Guohong Chen. Research and Application of Data Envelopment Analysis (DEA). Chinese Engineering Science. Vol. 05 (2003) No. 06, p. 88-94. 